\title{
Adoption of multiple climate- smart agricultural practices in the Gangetic plains of Bihar, India
}

Jeetendra Prakash Aryal

International Maize and Wheat Improvement Center (CIMMYT), El Batan, Mexico

M.L. Jat and Tek B. Sapkota

International Maize and Wheat Improvement Center (CIMMYT), New Delhi, India

Adoption of CSA practices

Arun Khatri-Chhetri

CGIAR Research Program on Climate Change Agriculture and Food Security (CCAFS), Borlaug Institute for South Asia (BISA), New Delhi, India

Menale Kassie

International Centre of Insect Physiology and Ecology (ICIPE), Nairobi, Kenya

Dil Bahadur Rahut

Socioeconomics Program, International Maize and Wheat Improvement Center (CIMMYT), El Batan, Mexico, and

Sofina Maharjan

International Maize and Wheat Improvement Center (CIMMYT), New Delhi, India

\begin{abstract}
Purpose - The adoption of climate-smart agricultural practices (CSAPs) is important for sustaining Indian agriculture in the face of climate change. Despite considerable effort by both national and international agricultural organizations to promote CSAPs in India, adoption of these practices is low. This study aims to examine the elements that affect the likelihood and intensity of adoption of multiple CSAPs in Bihar, India.

Design/methodology/approach - The probability and intensity of adoption of CSAPs are analyzed using multivariate and ordered probit models, respectively.

Findings - The results show significant correlations between multiple CSAPs, indicating that their adoptions are interrelated, providing opportunities to exploit the complementarities. The results confirm that both the probability and intensity of adoption of CSAPs are affected by numerous factors, such as demographic characteristics, farm plot features, access to market, socio-economics, climate risks, access to extension services and training. Farmers who perceive high temperature as the major climate risk factor are more likely to adopt crop diversification and minimum tillage. Farmers are less likely to adopt site-specific nutrient management if faced with short winters; however, they are more likely to adopt minimum tillage in
\end{abstract}

(C) Jeetendra Prakash Aryal, M.L. Jat, Tek B. Sapkota, Arun Khatri-Chhetri, Menale Kassie, Dil Bahadur Rahut and Sofina Maharjan. Published by Emerald Publishing Limited. This article is published under the Creative Commons Attribution (CC BY 4.0) licence. Anyone may reproduce, distribute, translate and create derivative works of this article (for both commercial \& noncommercial purposes), subject to full attribution to the original publication and authors. The full terms of this licence may be seen at http://creativecommons.org/licences/by/4.0/legalcode

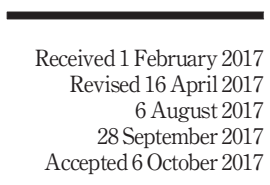

Accepted 6 October 2017 
IJCCSM

10,3

408

this case. Training on agricultural issues is found to have a positive impact on the likelihood and the intensity of CSAPs adoption.

Practical implications - The major policy recommendations coming from of our results are to strengthen local institutions (public extension services, etc.) and to provide more training on CSAPs.

Originality/value - By applying multivariate and ordered probit models, this paper provides some insights on the long-standing discussions on whether farmers adopt CSAPs in a piecemeal or in a composite way.

Keywords Climate change adaptation, Climate smart agricultural practices, Crop diversification, Minimum tillage, Site-specific nutrient management, Stress-tolerant seed varieties

Paper type Research paper

\section{Introduction}

Agricultural production in India has increased considerably since the Green Revolution (GR) because of the adoption of high-yielding varieties, chemical fertilizer, pesticides, irrigation and mechanization. Sustaining the gains of the GR is becoming increasingly difficult because of negative environmental externalities, such as groundwater depletion, soil fertility degradation and chemical runoff (Pingali, 2012; Singh, 2000) resulting from resource-intensive agriculture. Increasing climatic variabilities exert further pressure on the sustainability of the existing production system. Recently, climate-smart agricultural practices (CSAPs) have been accepted as methods to address challenges because of climate change in Indian agriculture. National and international research organizations, donors and policymakers have been expending considerable resources to develop and promote these practices to increase agricultural productivity to feed the growing population and improve farmers' resilience to climate change. National Innovations in Climate Resilient Agriculture, National Mission for Sustainable Agriculture, Cereal System Initiatives in South Asia, Sustainable and Resilient Farming System Intensification and the CGIAR research program on Climate Change, Agriculture and Food Security (CCAFS) are some of these initiatives. Recent studies showed that most of the CSAPs have clear economic (Aryal et al., 2015; Erenstein et al., 2008; Khatri-Chhetri et al., 2016; Sapkota et al., 2015) and climate change adaptation benefits (Aryal et al., 2016; Sapkota et al., 2015). Despite the benefits of CSAPs and the considerable efforts by several organizations to promote them, the rate of their adoption by Indian farmers is still very low. Therefore, understanding the CSAPs adoption behavior of farm households is crucial to fine-tuning their design and promotion to drive adoption. This study assesses the factors that determine the probability and intensity of adoption of CSAPs in Bihar, India using cross-sectional data collected in the second half of 2013. The CSAPs considered in this study include site-specific nutrient management (SSNM), crop diversification (CD), minimum tillage (MT) and stress-resistant improved seed (IS) varieties.

In Bihar, almost 90 per cent of the population resides in the rural areas and nearly 80 per cent of them are employed in agriculture. The Indo-Gangetic Plains (IGP) of Bihar cover one of the most productive agricultural areas in India, thus increasing agricultural production in this region is crucial for ensuring national food security (Government of Bihar, 2012). However, agriculture in this region is now increasingly affected by climate variability and climate risks. Northern Bihar is generally a highly flood-prone area, whereas southern Bihar is highly drought-prone (Government of Bihar, 2012). Along with a flat topography, the concentration of rainfall between July and September (about 80 per cent of the total annual rainfall) is the major cause of flooding in northern Bihar. Nearly 74 per cent of the total geographical area of Bihar is 
flood prone and this constitutes about 17 per cent of the total flood-prone areas of India. However, Bihar also suffers from severe droughts when the summer monsoon lessens causing to less-than-normal rainfall. As Bihar lies at the crossroads of the wet eastern coastal regions and the relatively dry continental region of the western plain, regional variations in rainfall distribution and rainfall variability is much higher. Although the average annual rainfall in Bihar is $1,200 \mathrm{~mm}$, there are considerable variations across the northern and southern areas. Generally, the eastern and northern areas receive 2,000 mm rainfall, whereas it is less than $1,000 \mathrm{~mm}$ in the western and south-western parts, making them highly vulnerable to drought. Therefore, vagaries of rainfall, recurrent floods and droughts occur in the same season at the same place, severally affecting agriculture. Among the districts in the IGP, the districts in Bihar are found to be highly vulnerable to climate change (Sehgal et al., 2013). Therefore, attaining sustainable agriculture and reducing the vulnerability of agriculture to climate change through the use of CSAPs is a pre-requisite in this region (Aggarwal et al., 2013; Aryal et al., 2014; Sehgal et al., 2013).

CSAP addresses the intertwined challenges of sustainable farming, food security, and issues of changes in climate (FAO, 2013). The term CSAP encompasses farming practices that sustainably increase productivity, enhance resilience/adaptation, reduce greenhouse gasses (GHG) and help achieve national food security and development goals (FAO, 2013, 2010). Technically, any agricultural practices can be considered CSAP as long as they improve productivity or resource-use efficiency, reduce a community's exposure or vulnerability to climate change, reduce GHG emissions and increase carbon sequestration (Neufeldt et al., 2013). For example, the use of highyielding and stress-tolerant seed varieties/breeds, and the adoption of improved management practices stabilize and increase farm production even under adverse production conditions. Increased farm production and income enhance farmers' ability to cope with extreme weather events. Similarly, agricultural practices, such as MT, proper management of crop residues and precision NM, enhance sequestration of atmospheric carbon into agro-ecosystems and increase resource-use efficiency, thereby reducing GHG emissions without compromising yield.

Previous studies examine CSAPs' adoption in terms of a single technology/practice and typically fail to account for technology complementarity and substitution possibilities. However, farmers can adopt technologies as complements and substitutes that addresses their multitude of constraints such as moisture stress, low soil fertility, declining groundwater table, terminal heat stress and low crop productivity. If some portfolios of CSAPs are substitutes, agricultural policy needs to concentrate on making these combinations of CSAPs available to farmers. Conversely, if some portfolios of CSAP are complements, it is vital to find ways of offering these as packages because their partial adoption will not achieve the desired productivity or environmental outcomes. Technology adoption decisions can be path dependent: the choice of technologies adopted most recently by farmers may depend on their earlier technology choice. Complementarities among technologies increase income and reduce crop failure substantially, which further stimulates the adoption of multiple technologies (Kassie et al., 2015, 2013; Teklewold et al., 2013; Yu et al., 2012). Recent empirical studies in Africa demonstrate that the joint adoption of these technologies (MT, CDs and ISs) significantly increases net income and reduces production risk compared to the individual adoption of these technologies (Kassie et al., 2015; Teklewold et al., 2013), thus suggesting complementary effects. Therefore, analysis of technology adoption without proper controlling for technology inter-dependence could either underestimate or overestimate the influences of various factors on the decision to adopt (Wu and 
IJCCSM

10,3

Babcock, 1998). Applying multivariate and ordered probit (OP) models, this paper provides some insights on the long-standing discussions on whether farmers adopt CSAPs in a piecemeal or in a composite way. The multivariate and OP models acknowledge the possibility of correlations between adoption decisions across different CSAPs.

The remainder of the paper is outlined as follows: Section 2 deals with the econometrics model and estimation strategies used in the paper. Section 3 provides a brief overview of the study area, data and the variables used in the analysis. Section 4 presents the results and discussion while the last section concludes the study.

\section{Econometric model employed for analysis}

This study used a multivariate probit (MVP) model to assess the factors affecting the likelihood of adopting multiple CSAPs and an OP model for estimating the level of adoption of CSAPs.

\subsection{Multivariate probit model: to identify the determinants of adoption of multiple CSAPS}

A technology adoption decision is influenced by multiple factors. An individual farmer may need to adopt a mix of CSAPs to address a multitude of climate risks and agricultural production constraints. Given that many CSAPs are not mutually exclusive, the decision to adopt one of the CSAPs may influence the decision to adopt other CSAPs. Hence, attempting univariate modeling would exclude useful economic information about interdependent and simultaneous adoption decisions (Kassie et al., 2013) - therefore, we applied an MVP model.

MVP models, unlike univariate probit models, allow for potential correlation among the unobserved disturbances in the adoption equations and the relationships between the adoptions of different CSAPs. This means the model considers the possible complementarities (positive correlation) and substitutability (negative correlation) between the CSAPs. Estimation without considering trade-off and synergies of technology adoption leads to biased and inefficient estimates of the determinants of adoption (Greene, 2003). Such biases may lead to situations where researchers may observe the lack of adoption because of poor returns as complementary practices are not adopted. However, one may fail to account for this impact because the univariate models do not adequately correct for these complementarities. For example, many farmers who use MT may also use SSNM; yet, unless researchers analyze this effect, they will not be able to understand the factors that enhance the uptake of SSNM by the farm household.

Theoretically, a specific CSAP is more likely to be adopted if the utility from its adoption is greater compared to its non-adoption. Assume a $i^{t h}$ farm household $(i=1,2, \ldots, N)$ confronting a choice on whether to adopt the $j^{\text {th }}$ CSAPs (where $j$ represents the choice of SSNM $(L)$, MT $(M), \mathrm{CD}(D)$ and stress-resistant IS variety $(S))$ on its farm plot $(p=1, \ldots, P)$. Let $U_{0}$ and $U_{j}$ denote the benefits to the farm household from the adoption of conventional agricultural practices and CSAPs, respectively. A farm household chooses to adopt the $j^{\text {th }}$ CSAPs on its farm plot $p$ if the net benefit $\left(y_{i p j}^{*}\right)$ from the adoption of other available technologies is higher -i.e. $B_{i p j}^{*}=U_{j}^{*}-U_{0}>0$. In this case, the net benefit of the adoption of the CSAPs is a latent variable (i.e. $y_{i j \mathrm{j}}^{*}$ ), which is determined by the observed household, farm plot and location information $\left(X_{i p}\right)$ and the error term $\left(\varepsilon_{i p}\right)$ as follows:

$$
y_{i p j}^{*}=X_{i p}^{\prime} \beta_{j}+\varepsilon_{i p} \quad(j=L, M, D, S)
$$


Authors can present equation (1) in terms of the indicator function. In the current study, the unobserved preferences in equation (1) transform into the observed binary outcome equation for each CSAP choice as follows:

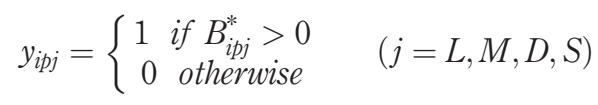

In the MVP model, with the prospect of adopting multiple CSAPs, the error terms jointly follow a multivariate normal distribution with zero conditional mean and variance normalized to unity, i.e. $\left(u_{L}, u_{M}, u_{D}, u_{S}\right) \rightarrow^{M V N}(0, \Omega)$ and the covariance matrix $(\Omega)$ is given by:

$$
\Omega=\left[\begin{array}{cccc}
1 & \rho_{L M} & \rho_{L D} & \rho_{L S} \\
\rho_{M L} & 1 & \rho_{M D} & \rho_{M S} \\
\rho_{D L} & \rho_{D M} & 1 & \rho_{D S} \\
\rho_{S L} & \rho_{S M} & \rho_{S D} & 1
\end{array}\right]
$$

where $\rho$ refers to the correlation between error terms - if error terms correlation shown in the off-diagonal elements of the variance-covariance matrix become non-zero, then equation (2) becomes an MVP model.

A pooled MVP model is consistent if the unobserved heterogeneities (ability, motivation, land quality,etc.) are not correlated with observed covariates. The data used in this study afford us a panel structure arising from repeated plot observations per household which authors exploited to estimate equation (2) with the Mundlak approach to control for unobserved heterogeneities (Mundlak, 1978). Mundlak's approach involves including the mean of plot-varying explanatory variables as additional covariates in the regression model. Many studies (Teklewold et al., 2013; Kassie et al., 2013) have applied this approach using cross-sectional multiple plot observations.

\subsection{Ordered probit model: for estimating the level of adoption of CSAPS}

To analyze the factors determining the intensity of CSAP adoption, the authors applied an OP model. In this case, the dependent variable can take values $0,1,2,3$ and 4, depending upon whether a farmer has not used any CSAPs or used at least one, or two or three or four. This is done because the MVP model specified above cannot differentiate how many CSAPs are used by the farmers. When farmers adopt multiple CSAPs, it is difficult to define a cutoff point between adopters and non-adopters, while examining the intensity of CSAP adoption by farmers (Wollni et al., 2010). In our study area, some farmers adopt some CSAPs on part of their land; thus, using a fraction of its area under CSAP as a variable to measure the intensity of adoption (as is often done in other studies) is difficult. To overcome this problem, the authors used the number of CSAPs adopted by farmers as a dependent variable measuring the intensity of adoption and applied an OP model (D'Souza et al., 1993; Teklewold et al., 2013). Poisson regression could have been used assuming that number of CSAPs adopted as a count variable; however, it assumes the equal probability of adoption of each alternative CSAP. In our case, this is not a valid assumption because the likelihood of adopting the first CSAP might differ from the probability of adopting the second and so on. This happens mainly because of the exposure of farmers to information about CSAPs. As the authors have data on the farm plot level, this gives us a possibility to also use both pooled and random effect models and Mundlak's (1978) approach by including the mean of 
IJCCSM

10,3

412

plot varying covariates that help to capture the correlation between observed covariates and unobserved heterogeneity (Teklewold et al., 2013).

\subsection{Concerns in estimations of the econometric models}

Multiple factors influence farmers' decisions to adopt agricultural technologies (Birthal et al., 2015; Doss, 2003; Kassie et al., 2010). Hence, it is essential to control for a number of factors in estimating the MVP model. However, when the authors add a number of explanatory/ independent variables to the MVP model, the authors may risk the problem of multicollinearity and the need for a large sample size. The authors applied a condition index to test for the possible multicollinearity (Belsley, 1991; Belsley et al., 2005). The simple decision rule is that if the value of the condition index is below 30, it indicates that there is no severe problem of multicollinearity. Moreover, estimators are projected based on the asymptotic theory and thus, it necessitates a sufficiently large sample size. The number of observations ought to be higher than $1.5 k(k+1)$, where $k$ refers to the total number of variables used in the MVP model (Behera et al., 2015; Jöreskog and Sörbom, 1993). If the number of observations is less than an obligatory number, the asymptotic variancecovariance matrix is unlikely to be positive definite. This is exhibited in biased inference caused by poor estimates of parameter variance-covariance.

\section{Study area, data and description of variables}

The data for this study were collected in 2013 from 641 farm households residing in 12 villages of Vaishali district of Bihar state, India (Table I and Figure 1). A multi-stage sampling method was applied to select the sample households in the study. In the first stage, study villages within the district were chosen using a stratified random sampling method. In the second stage, a census of around 75 per cent of households in the village was taken to collect basic information, such as main occupation, crops grown, operational land holdings and age and gender of the household head. Finally, based on the information gathered in the village census, the sample households were randomly selected from each village. The authors collected information that includes household characteristics, farm plot characteristics, access to credit, extension services, market characteristics and information on training received, adoption of CSAPs (including MT), CD and stress-resistant IS varieties.

Vaishali district lies in the Eastern IGP. It has a sub-humid tropical climate with average annual rainfall of about $1150 \mathrm{~mm}, 80$ per cent of which is received between July and September. Although rice and wheat are the major crops, maize is emerging as an

\begin{tabular}{lc}
\hline Village name & Sample size \\
\hline Bhatha Dasi & 63 \\
Bilandpur & 68 \\
Dedhpur & 46 \\
Dhabhaich & 46 \\
Laxminarayanpur & 44 \\
Mirpur & 55 \\
Mukundpur & 69 \\
Panapur Camp & 56 \\
Raja Pakar & 70 \\
Rampur Ratnagar & 45 \\
Rasalpour & 48 \\
Varishpur & 31
\end{tabular}




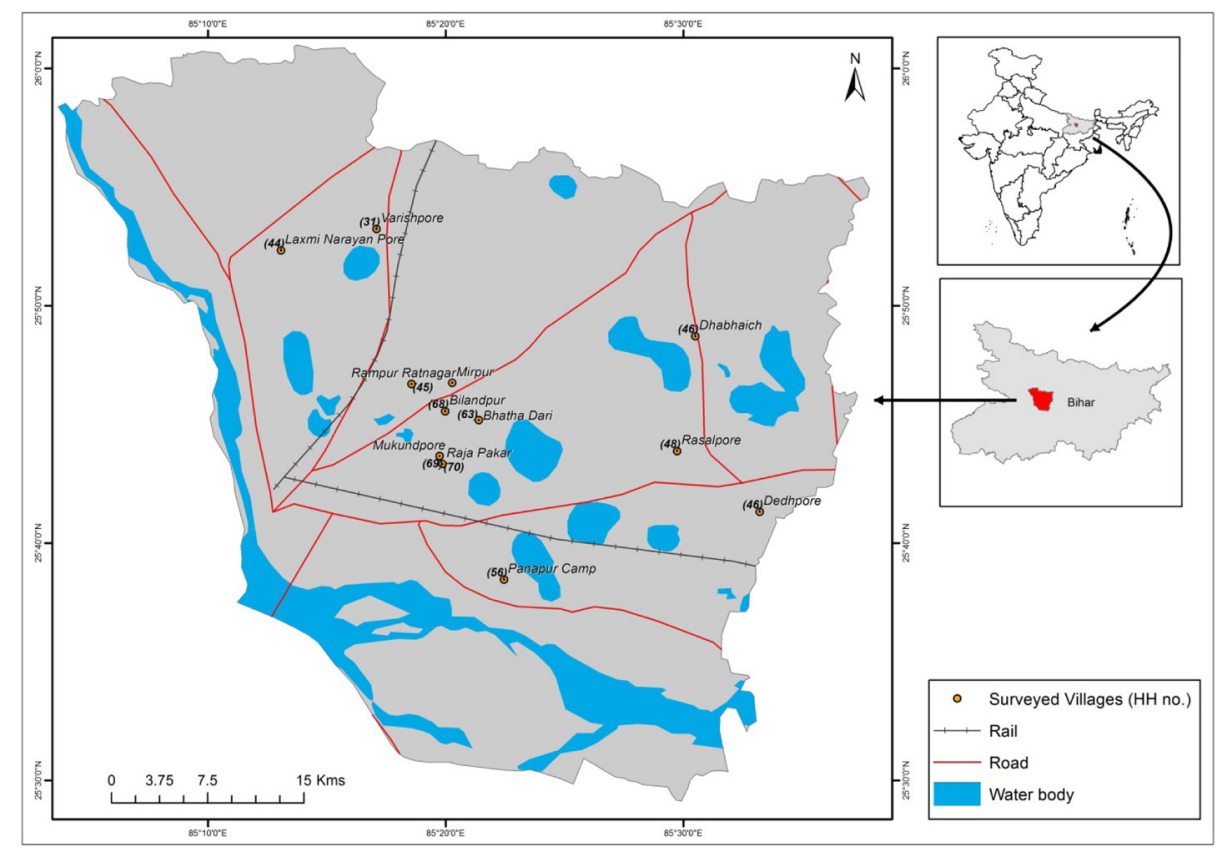

Adoption of CSA practices

413

alternative crop in this area. The average size of land holdings in Vaishali district is 0.51 ha. Land fragmentation is a critical issue in Vaishali with an average farm plot size of 0.12 ha.

\subsection{Description of variables used in the study and hypotheses to be tested}

The descriptive statistics and explanation of the variables (both dependent and explanatory) employed in the study are presented in Table II.

3.1.1 Dependent/explained variables. CD (legume integration in crop rotations and intercropping) is one of the CSAPs under study. About 20 per cent of the total farm-plots under study follow $\mathrm{CD}$. Such practices help farmers to diversify to reduce risk and increase productivity and income through improving soil fertility, controlling for pests and weed infestation (Bradshaw et al., 2004; Liebman and Dyck, 1993; Lin, 2011; Shiferaw et al., 2012; Teklewold et al., 2013; Kassie et al., 2015).

The adoption of improved technologies, such as improved and stress-tolerant varieties, boosts farmers' adaptive and resilience capacities. Farmers mainly use drought-tolerant varieties of rice such as Swarna Sub 1, and in some cases were found to have used submergence-tolerant varieties. In addition to increasing income through improving productivity, stress-tolerant varieties can stabilize productivity through minimizing the effects of climate change and variability (Sarkar et al., 2006).

MT, which refers to either reduced tillage or zero tillage with residue retention, is another CSAP under study. It entails minimum soil disturbance and allowing crop residue or stubble to remain on the plot with the accompanying benefits of better soil aeration, carbon sequestration, improved soil fertility and an increased water-holding capacity of soil (Lal, 2004, 1997; Sapkota et al., 2015). It can cope with water-stress situations by conserving 


\section{IJCCSM \\ 10,3}

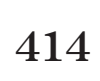

Variables
Dependent Variables
$\mathrm{CD}(\mathrm{D})$

IS (D)

MT (D)

NM (D)

Total CSAPs

Independent variables

Household characteristics

Male headed household (D)

General caste (D)

Age (C)

Literate HH head (D)

Literate spouse of $\mathrm{HH}$ head (D)

Family size (C)

Migrant (D)

Farmland characteristics

Tenure of plot (D)

Area of plot (C)

Soil fertility (D)

Soil depth (D)

Land slope (D)

Distance (C)

Economic and social capital

Land operated (in ha) (C)

TLU (C)

Asset index

Credit access (D)

Association in group (D)
$0.92 \quad 0.27 \quad 1$ if male and 0 if female

$0.33 \quad 0.47 \quad 1$ if general caste and 0 otherwise

$51 \quad 13$

$0.64 \quad 0.48$

$0.27 \quad 0.44$

$6.40 \quad 2.88$

$0.32 \quad 0.47$

Number of family members

1 if at least one migrant member and 0 otherwise

$0.76 \quad 0.43 \quad 1$ if owned and 0 if rented in

$0.12 \quad 0.13$

$0.46 \quad 0.50$

$0.15 \quad 0.36$

$0.47 \quad 0.50$

$0.75 \quad 1.05$

$0.51 \quad 0.52$

$0.70 \quad 0.82$

$0.30 \quad 0.53$

$0.39 \quad 0.49$

$0.11 \quad 0.31$

Access to market and agricultural extension service and training

$\begin{array}{lll}\text { Distance to local market (C) } & 2.46 & 1.49\end{array}$

Distance to agriculture $\quad 4.67 \quad 3.71$

extension service $(\mathrm{C})$

Training (D)

$0.24 \quad 0.41$

Main source of information

Farmer to farmer

$0.46 \quad 0.50$

communication (D)

Government extension (D)

0.03

0.12
Area of plot in hectare

1 if good and 0 otherwise

1 if deep and 0 if shallow

1 if gentle slope and 0 if medium/steep slope

Distance from house to plot in $\mathrm{Km}$

Total land operated

Livestock owned

Household asset index

1 if farmer has credit access and 0

otherwise

1 if membership in any association and 0 otherwise
Distance to local market from house (in $\mathrm{km})$

Distance to agriculture extension service from house (in $\mathrm{km}$ )

1 if participated in agricultural training and 0 otherwise

1 if information received from neighbor/ relative farmer/cooperative and 0 otherwise

1 if information received from government extension service and 0 otherwise
Table II.

Description of

variables used in the study

(continued) 


\begin{tabular}{|c|c|c|c|c|}
\hline Variables & Mean & SD & Variable Description & CSA practices \\
\hline ICT (D) & 0.03 & 0.17 & $\begin{array}{l}1 \text { if information received from radio, } \\
\text { newspaper, TV, mobile and } 0 \text { otherwise }\end{array}$ & \\
\hline $\begin{array}{l}\text { Seed traders/private company } \\
\text { (D) }\end{array}$ & 0.28 & 0.45 & $\begin{array}{l}1 \text { if information received from seed } \\
\text { traders/private company and } 0 \text { otherwise }\end{array}$ & \\
\hline \multicolumn{4}{|c|}{ Climate risks experienced by household over the past five years } & 415 \\
\hline Heat stress (D) & 0.72 & 0.45 & $\begin{array}{l}1 \text { if farmer experienced heat stress and } 0 \\
\text { otherwise }\end{array}$ & \\
\hline Less rainfall (D) & 0.91 & 0.28 & $\begin{array}{l}1 \text { if farmer experienced less rainfall and } 0 \\
\text { otherwise }\end{array}$ & \\
\hline Decrease winter (D) & 0.27 & 0.44 & $\begin{array}{l}1 \text { if farmer experienced decrease winter } \\
\text { and } 0 \text { otherwise }\end{array}$ & \\
\hline Total number of HH (plot) & 004) & & & \\
\hline
\end{tabular}

Notes: C - Continuous variable; D-Dummy variable

Table II.

moisture and utilizing residual moisture during planting, and with temperature-stress by advancing the planting time of winter crops after the harvest of summer crops. About 19 per cent of the farm plots operated by the sample farmers are under MT.

SSNM contributes to the management of nutrients needed for crops, thereby improving resource-use efficiency and lowering GHG emissions from agriculture (Sapkota et al., 2014). About 18 per cent of the total farm-plots received SSNM.

The dependent variable, total CSAPs, refers to the number of CSAPs used by the farmers in the same plot in 2012. This number ranges from 0 to 4 in our case.

3.1.2 Independent/explanatory variables. The authors specified the model based on past theoretical frameworks and empirical adoption literature (Aryal et al., 2014, Aryal and Holden, 2011; Erenstein and Farooq, 2009; Feder and Umali, 1993; Kassam et al., 2009; Kassie et al., 2013, 2010, 2015; Pender and Kerr, 1998; Teklewold et al., 2013). Description of the explanatory variables and hypothesis about their effects on the dependent variable(s) are discussed below.

3.1.2.1 Household characteristics. A household's socio-economic and demographic characteristics consist of the main attributes of the head of the household, such as education, literacy status, age and gender, family size, spouse's literacy status and migration status. Household characteristics generally stimulate technology adoption decisions under market imperfection and institutional failure (de Janvry et al., 1991; Holden et al., 2001). Literate household heads have better capability and knowledge to access and absorb new information, and are more likely to have more non-farm income, which in turn influence the decision to adopt new technology (Chander and Thangavelu, 2004). Generally, agricultural technology adoption can be a part of an overall household strategy and thus, the spouse's literacy status might also affect it. The age of the household head is worth examining as older people have more experience with farming systems and often a greater accumulation of physical and social capital; however, they also often have short-term planning horizons, a loss of energy and more risk aversion (Albert and Duffy, 2012). Migration, which refers here to families with at least one member currently living elsewhere, reduces household labor endowment and increases access to alternative income sources. Therefore, it is assumed that migration enables the adoption of new labor-saving technologies.

3.1.2.2 Farmland characteristics. Farm plot features (farm plot size, tenancy status, soil fertility, soil depth, plot slope, and distance to plot from homestead) are included in the analysis. 
IJCCSM

10,3

416
The soil fertility, soil depth, plot slope, and distance to the plot are provided separately for different parcels (plot by plot). This is crucial to control for the possible impacts of farmland attributes on technology adoption. For instance, distant plots not only require more cost for transporting inputs but are also more difficult to monitor. Thus, farmers may be less keen to embrace new technology on distant plots. Land fragmentation is extremely high and farmers run multiple small plots in Bihar. Small farm plot size can be a limiting factor to mechanization and may make farmers less likely to adopt MT on such plots.

3.1.2.3 Economic and social capital. To control for wealth differences among households, the authors included several economic capital variables such as farm size, livestock ownership, household asset index and labor force available in the household in the analysis. For social capital, the authors used variables such as membership in an organization (e.g. farm cooperatives) or any other farm clubs/input traders/sellers and other groups. The authors used caste as one of the social capitals, signifying variables, as it affects access to public domains in rural communities in South Asia (Aryal and Holden, 2013, 2012). Caste restricts or facilitates a household's participation in some markets and access to information (Yamano et al., 2015). The authors hypothesize that the general caste group is more likely to adopt CSAPs than the backward and scheduled caste groups.

3.1.2.4 Markets and institutional services. Access to markets and other institutional services are important variables, as they influence transaction costs. Distance to village markets is used as a proxy for market access, while the distance to extension services is considered a proxy for access to institutional services.

3.1.2.5 Source of information and training. Adoption of CSAPs also depends on the access to information and training received. Farmers receive information through multiple sources including farmer-to-farmer communication, extension services, information and communication technology and private traders. As the training on related topics such as soil-water management and MT, also influences the farmers' likelihood of adopting those technologies, the authors controlled for this in the analysis.

3.1.2.6 Climate risks. Agriculture faces numerous risks arising from changes in climate. Therefore, farmers embrace new farming practices to adapt to those climate risks. Farmers also stated that heat stress, less rainfall, and a decrease in winter are three leading climate risks experienced during the last five years. These three major climate risks were included in the analysis to investigate the impacts of these shocks on the adoption of CSAPs.

Village dummies are included in the regression to control for spatial differences such as rainfall, infrastructure and quality of service delivery.

\section{Results and discussion}

\subsection{Determinants of multiple adoptions of CSAP: Multivariate probit model}

Farmers adopted different CSAPs concurrently; this shows that there is a chance of a correlation between their choices of CSAPS. This is tested using pair-wise correlation coefficients across the residuals of an MVP model. Most of the estimated pair-wise correlation coefficients across the residuals of MVP model are statistically significant (Table III), thereby supporting our hypothesis that the error terms of the multiple decision equations are correlated. The likelihood ratio test $[\operatorname{chi} 2(6)=78.48$; Prob $>$ chi2 $=0.000]$ also rejected the null hypothesis that the covariance of the error terms across equations are not correlated. This justifies the rationale for using the MVP model and confirms that adoption of multiple CSAPs in Bihar is not mutually exclusive. Practicing CD and MT are significantly and negatively associated (Table III); implying that farmers consider these CSAPs substitutes. Other CSAP combinations such as MT and IS, MT and SSNM and IS 
and SSNM are significantly and positively associated, implying that farmers consider these as complements (i.e. farmers apply them simultaneously).

Table IV shows the results of the MVP model estimated using the maximum likelihood method on farm plot-level observations. Although the authors have 2,004 farm plots, the authors used only 1,926 farm plot-level observations because of inconsistencies in the remaining observations. Our estimates show that the model fits the data well as the Wald test $[$ Wald chi2 $(172)=1362.16$; Prob $>$ chi2 $=0.000)$ ] of the null hypothesis, that all regression coefficients in each equation are jointly equal to zero, is rejected. This shows the relevance of the model to account for the unobserved correlations across decisions to adopt multiple CSAPs.

Results show that the explanatory variables affecting decisions to adopt differ substantially across the CSAPs. Unlike other studies, the authors found that male-headed households are less likely to adopt $\mathrm{CD}$ and IS. For example, when compared to female-headed households, maleheaded households are 0.42 per cent less likely to adopt CD. Compared to the backward/ scheduled caste group, farmers belonging to the general caste group are more likely to adopt IS and NM; whereas, they are less likely to adopt MT. These results corroborate the findings by Aryal and Holden (2011) and Yamano et al., (2015) that caste position affects farmers' investment decisions. Older household heads are less likely to adopt CD and NM; the former may be because of a higher requirement of labor, while the latter may be attributable to the fact that older household heads are less familiar with this relatively newer technology. Older household heads are more likely to adopt MT and IS; however, the result is significant at the 10 per cent level only. Literacy status of the household head and spouse are an important factor influencing the CSAP adoption decision. Households with a literate household head are more likely to adopt MT, IS and NM while those with literate spouses are less likely to adopt CD but more likely to adopt MT and NM, indicating that they are more likely to choose labor saving CSAPs. Migration is significantly and negatively associated with the likelihood of adopting $\mathrm{NM}$ and IS with 5 and 1 per cent levels of significance, respectively, while it is positively associated with the adoption of $\mathrm{CD}$ at the 10 per cent level of significance.

Several farm land characteristics are found to have influenced the probability of adopting CSAPs. Land tenure affects adoption of CD and MT; owner-cultivated plots are less likely to adopt CD and MT. This result is consistent with earlier studies on technology adoption (i.e. Feder and Umali, 1993; Kassie et al., 2013, 2010). In Bihar, tenants need to seek permission from the landlords to grow crops on the rented plots, and thus, CD is less likely in such cases. Another important issue that inhibits mechanization in Bihar is land fragmentation. The authors controlled for this using the area of the farm plots. Our results show that the area of the plot does not affect CD, IS and NM while it affects the adoption of MT significantly and positively. This justifies our hypothesis that larger plots are more

\begin{tabular}{lcc}
\hline Correlation pairs & Coefficient & Standard error \\
\hline Crop diversification $\times$ MT & $-0.267^{* * * *}$ & 0.061 \\
Crop diversification $\times$ IS & -0.139 & 0.169 \\
Crop diversification $\times$ SSNM & $-0.330^{* * * *}$ & 0.058 \\
MT $\times$ IS & $0.268^{* * *}$ & 0.101 \\
MT $\times$ SSNM & $0.289^{* * *}$ & 0.056 \\
IS $\times$ SSNM & $0.182^{* *}$ & 0.088
\end{tabular}

Notes: LR test of: rho $21=$ rho31 $=$ rho41 $=$ rho32 $=$ rho42 $=\operatorname{rho} 43=0$ : $\operatorname{chi} 2(6)=78.48$; $\operatorname{Prob}>\operatorname{chi} 2=$ 0.000; Significance level: $5 \%$ level $* * ; 1 \%$ level ***

Adoption of CSA practices

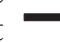




\section{IJCCSM \\ 10,3}

\section{8}

Table IV.

Estimates of the MVP model

\begin{tabular}{|c|c|c|c|c|}
\hline Dependent variables & $\mathrm{CD}$ & MT & IS & NM \\
\hline \multicolumn{5}{|c|}{ Household $(H H)$ characteristics } \\
\hline Male headed HH & $-0.421 * *(0.176)$ & $0.024(0.200)$ & $-1.469 * * *(0.361)$ & $-0.294(0.182)$ \\
\hline General caste & $0.062(0.106)$ & $-0.441 * * *(0.106)$ & 0.576 *** $(0.223)$ & $0.121 * * *(0.017)$ \\
\hline Age of $\mathrm{HH}$ head & $-0.013 * *(0.006)$ & $0.006 *(0.004)$ & $0.015 *(0.008)$ & $-0.005 * *(0.002)$ \\
\hline Literate $\mathrm{HH}$ head & $0.167(0.111)$ & $0.054 * *(0.019)$ & $0.703 * * * *(0.250)$ & $0.212 *(0.121)$ \\
\hline & $0.402 * * * *(0.121)$ & $0.393^{* * * *}(0.112)$ & $-0.198(0.202)$ & $0.294 * *(0.117)$ \\
\hline Family size & $-0.003(0.015)$ & $-0.003(0.016)$ & $-0.069 * *(0.034)$ & $0.017(0.016)$ \\
\hline Migrated & $0.157 *(0.094)$ & $0.111(0.101)$ & $-0.700^{* * * *}(0.245)$ & $-0.144 * *(0.080)$ \\
\hline \multicolumn{5}{|c|}{ Farm land characteristics } \\
\hline Tenure of plot & $-0.132 * * *(0.012)$ & $-0.087 * * *(0.016)$ & $0.121(0.220)$ & $0.098(0.113)$ \\
\hline plot & $-0.048(0.334)$ & $0.112 * * *(0.036)$ & $0.746(0.597)$ & $-0.278(0.385)$ \\
\hline Soil fertility & $0.369 * * *(0.094)$ & $-0.470 * * *(0.101)$ & $-0.698 * * *(0.210)$ & $0.047(0.101)$ \\
\hline & $0.237 * *(0.116)$ & $-0.610 * * *(0.167)$ & $-0.822(0.518)$ & $-0.465 * * *(0.149)$ \\
\hline Land slope & $-0.234 * *(0.091)$ & $0.255 * * *(0.099)$ & $-0.284(0.211)$ & $0.646 * * *(0.099)$ \\
\hline Distance to plot & $-0.006(0.041)$ & $-0.125 * * *(0.051)$ & $0.063(0.075)$ & $-0.035^{* *}(0.017)$ \\
\hline \multicolumn{5}{|c|}{ Economic and social capital } \\
\hline & $0.264 * *(0.104)$ & $0.163 * * *(0.011)$ & $0.067 * * *(0.023)$ & $0.136 * *(0.062)$ \\
\hline Livestock owned & $0.215^{* * * *}(0.053)$ & $0.198 * * *(0.059)$ & $0.226 *(0.138)$ & $0.205^{* * * *}(0.057)$ \\
\hline Asset index & $0.343 * * *(0.133)$ & $0.275^{* *}(0.132)$ & $0.336^{* *}(0.171)$ & $0.256^{* *}(0.119)$ \\
\hline Credit access & $-0.537 * * *(0.102)$ & $0.575 * * *(0.113)$ & $-0.337(0.260)$ & $0.680 * * *(0.113)$ \\
\hline Association in group & $0.297 * *(0.143)$ & $0.394 * *(0.188)$ & $-0.411(0.364)$ & $0.537 * * *(0.184)$ \\
\hline
\end{tabular}

Access to market and agricultural extension services and training

Distance to market $-0.035(0.034)-0.112 * * * * 0.040)$

Distance to extension service $-0.061 * * *(0.015)-0.045^{* * * *}(0.013)-0.0$ $-0.080(0.083)-0.087^{* *}(0.040)$

Training $0.645 *(0.359) \quad 0.162 * *(0.073) \quad 0.115 * *(0.052)$

$0.058 * *(0.029)$

Source of information

Farmer-to-farmer communication

Government extension service

$0.838 * * * *(0.320)$

$0.561^{* * *}(0.112)$

$0.914 * * *(0.287)$

$0.084 *(0.037) \quad-0.179(0.327)$

$0.932 * * *(0.125)$

ICT

$0.818^{*}(0.401) \quad 0.516 *(0.307) \quad 0.169 * * *(0.039)$

$-0.413(0.292)$

Private traders

$-0.156(0.108)$

$0.127 * *(0.063)$

$0.167^{* *}(0.075)$

$0.264 * *(0.107)$

Major climate risks

High temperature

Decreasing rainfall

Short winters

$$
\begin{array}{r}
0.639 * * * *(0.113) \\
0.183(0.165) \\
0.051(0.115)
\end{array}
$$
$0.504 * * *(0.108) \quad 0.482 * *(0.231) \quad 0.081(0.107)$ $0.064(0.154) \quad 0.143^{* * * *(0.056)} \quad-0.159(0.161)$ $1.378 * * *(0.152) \quad-0.180(0.228)-0.605^{* * * *}(0.135)$

Joint significance of village dummies

$\mathrm{Chi}^{2}(11)$

Prob > Chi' ${ }^{2}(11)$

74.41

0.000

Constant $-1.920 * * *(0.395)$

84.62

0.000

63.11

0.000

$1.114^{* * * *}(0.391)-1.694^{* * * *}(0.734)$

222.19

0.000

1926

1926

1926

$0.378 * *(0.167)$

1926

Notes: LR test of: $r$ rho $21=$ rho31 $=$ rho41 $=$ rho32 $=$ rho42 $=$ rho43 $=0: \operatorname{chi} 2(6)=78.48$ Prob $>$ chi2 $=0.000$; Wald chi2(156) $=1362.16$; Prob > chi2 $=0.000$; Log likelihood $=-1916.92$; Significance level: $10 \%$ level $(*)$; $5 \%$ level $* * ; 1 \%$ level $* * *$ 
likely to receive MT as it requires the operation of machines on the plot which is more difficult on small plots. Farmers are more likely to adopt CD on plots with deep and fertile soil. Contrary to our hypothesis, farmers are less likely to adopt MT and IS on plots with deep soil. Consistent with earlier studies (Feder and Umali, 1993; Kassie et al., 2013, 2010), our results show that farmers are less likely to adopt MT and IS on the plots when the soil quality appears to be good (i.e. plots with deep soil depth).

The economic and social capital of the farm household affects their decisions to adopt technology. Our results show that farmers of large farms are more likely to adopt all CSAPs under study. For instance, larger farm size is positively associated with the adoption of MT and IS; the coefficients are significant at the 1 per cent level. Households with more livestock ownership have a higher probability of adopting CD, MT, IS and NM. Access to credit has variable effects on technology adoption: it increased the probability of adopting MT and NM while it decreased the probability of $\mathrm{CD}$ and IS. Association in village cooperatives and groups is more likely to increase the adoption of CD, MT and NM.

Distance to market from the household is negatively and significantly associated with the adoption of MT and NM; however, it has no significant association with other CSAPs. This is plausible because MT requires machines, which are mostly used on a custom hire basis and are available only in the market center in Bihar. Households that are far from extension services are less likely to adopt CD, MT and IS.

Farmers obtain information about the technologies and farming practices from different sources such as other farmers, government extension services, information and communication technologies (ICTs) (i.e. information through mobile phones and private traders. The decisions to adopt different technologies are affected by the type of information sources. As per our $a$ priori assumption, the results show that farmer-to-farmer communication is positively related to the adoption of $\mathrm{CD}$ (significant at the 1 per cent level). Information from government extension services increases the probability of adopting CD and MT, while it does not affect other CSAP adoptions. This is possible because government extension agents are less informed about the relatively newer CSAPs in Bihar, though addressing the impact of climate change on agriculture is a matter of serious concern. ICTs (especially the use of mobile phones to provide information on agricultural technology and weather information) are becoming a popular method of communication in India (Birthal et al., 2015; Rao, 2007). Use of ICTs is associated positively and significantly with the adoption of CD, MT and IS. Private traders are also an important source of information about CSAPs now. Farmers receiving information from private traders are more likely to adopt MT, IS and NM. This is plausible in Bihar, as the majority of traders are linked to major products such as rice, wheat, and maize; thus, they focus on providing information that expands their businesses. Participation in agricultural training is positively and significantly associated with the likelihood of adopting CSAPs, especially CD, MT, IS and NM.

Farmers' choice of CSAPs also depends on their experiences regarding climate risks. Farmers experiencing high temperatures as major climate risks over the past five years are more likely to adopt CD, MT, and IS. Farmers are adopting IS (especially stress-tolerant varieties, such as Swarna sub1) as a result of experiencing climate risks, such as heat stress because of high temperature (Yamano et al., 2015). Another climate risk, decreasing rainfall, is significantly and positively associated with the adoption of IS. Farmers facing short winters are more likely to adopt MT and less likely to adopt NM. One of the main reasons behind this could be the use of the zero tillage (in our case the authors call it MT) wheat production system, in which farmers can plant wheat earlier than they do conventionally and thereby the wheat escapes the terminal heat if the winter is short. (Sapkota et al., 2015). 


\section{IJCCSM 10,3}

\subsection{Factors explaining intensity of CSAPs adoption}

Farmers have adopted multiple CSAPs in the study area; however, the intensity of adoption varies from 1 to 4 CSAPs in the same farm plot by the sampled farm households. The authors estimated the OP model to examine the factors explaining the intensity of CSAPs adoption. As a direct interpretation of the coefficients of an OP model is less informative, the authors calculated marginal effects on each outcome (i.e. level of intensity [Table V]). The chi ${ }^{2}$ statistic for the OP model is statistically significant at less than the 1 per cent level of significance. This indicates that the null hypothesis - that joint test of all slope coefficients equal zero - is rejected.

Results show that several factors influence the intensity of CSAP adoption. Gender of the household head, caste, literacy status of household head and migration are the major household characteristics variables affecting the intensity of CSAP adoption. The number of CSAPs adopted is significantly lower among the male-headed households compared to female-headed households. Unlike the adoption decision (as shown in Table IV), the variable "literate spouse" is found to have no effect on the intensity of CSAPs used (Table V). This indicates how the same variable can have a differing impact on the decision to adopt CSAPs and the intensity of adoption. Households with at least one migrated member have a significant and positive effect on the number of CSAPs used, with varying marginal probabilities of each outcome.

Compared to the decision to adopt CSAPs (Table IV), only three farm land characteristics variables including tenure status, the size of and distance to the plot, are found to have a significant impact on the intensity of CSAP adoption. Owner-cultivated plots have a higher intensity of CSAPs used than rented plots (significant at the 1 per cent level). Larger plots have a positive association with the intensity of adoption, indicating that land fragmentation in Bihar is a constraining factor to CSAP adoption. Plots farther from the homestead received fewer CSAPs compared to plots nearer the homestead. This could be because of the higher transportation and monitoring costs to farmers.

Wealthier households (households with higher asset indices) are found to have a higher intensity of adopting CSAPs. Association in groups increases the level of CSAPs used positively and significantly. Credit access has a negative and significant effect on CSAPs used. This is plausible in the study area as credit taken for agricultural purposes is often used for other social purposes. The focus group discussion with the farmers in the study area revealed that in several cases, credit is used to cover marriage, dowry and medical expenses. Access to markets and agricultural extension services are crucial factors to enhance the level of CSAP adoption. Our results show that the variables of increasing distance from markets and extension services have negative and significant effects on the intensity of CSAPs used.

Information sources, including "farmer-to-farmer communication", "government extension services" and "information and communication technology" are positively and significantly associated with the level of CSAP adoption. This indicates the importance of farmers' access to these information sources and mobilizing resources to upgrade these facilities (Birthal et al., 2015). Moreover, this indicates that national and international agricultural institutions are effective in enhancing farmers' knowledge about the CSAPs required to address the climate risks in agriculture. Training on soil management and tillage, and CD has a positive and significant effect on the level of CSAPs used.

Farmers who faced high temperatures as a major climate risk over the past five years have significantly higher levels of CSAP adoption, opposed to the farmers who faced short winters as the major climate risk over the last five years. 


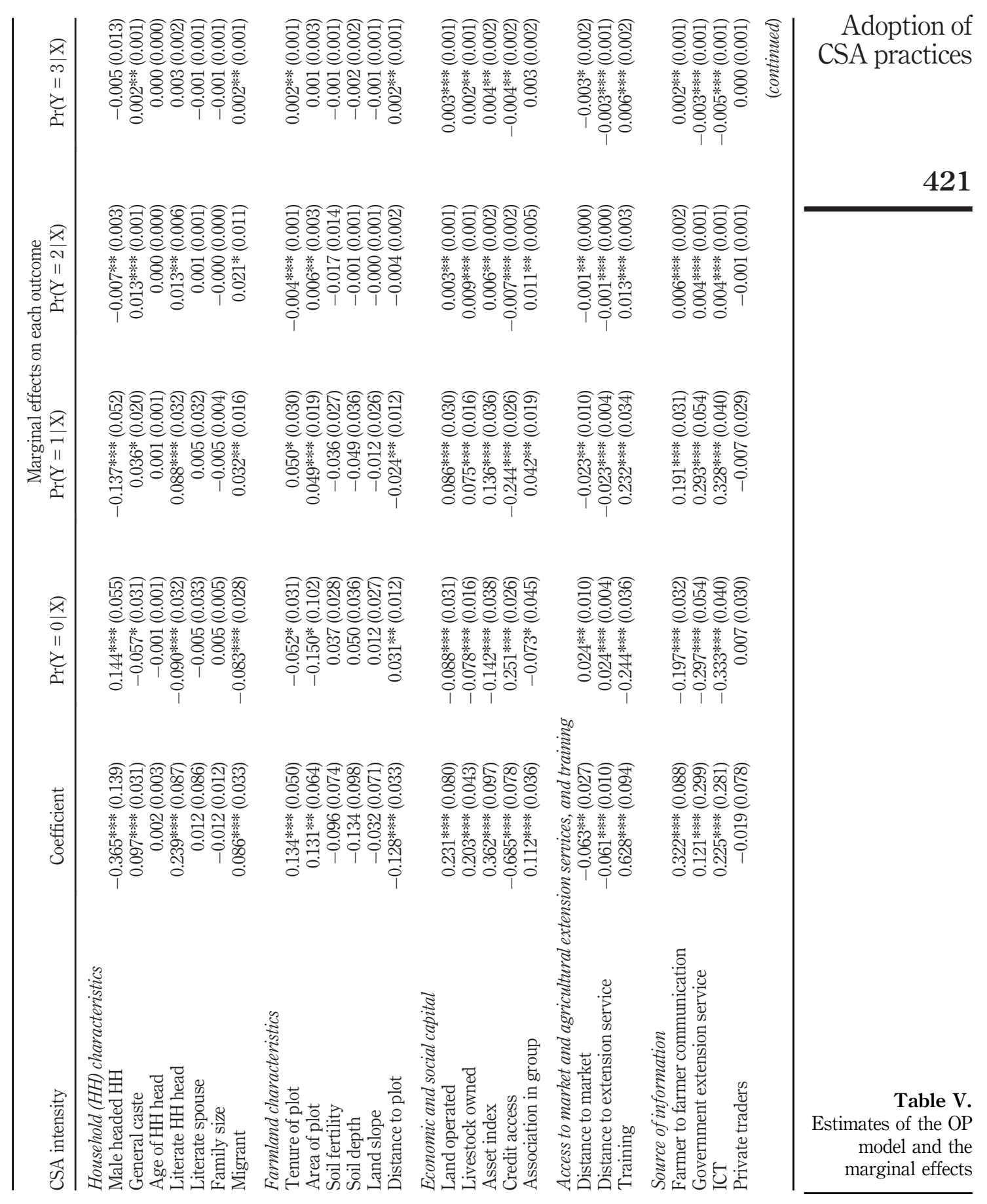


IJCCSM

10,3

422

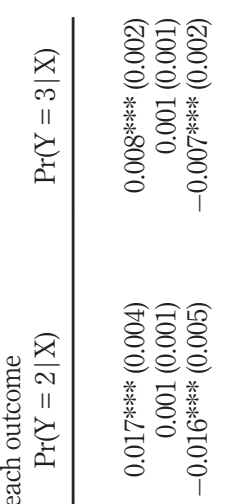

ळ్

ڤั

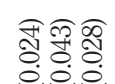

着然

क्ष

종영

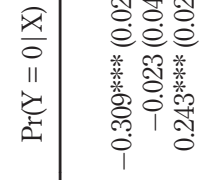

隶

放

.

하용

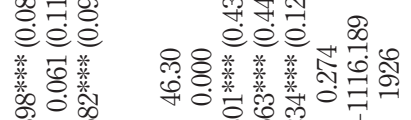
年

ผี

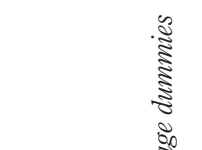

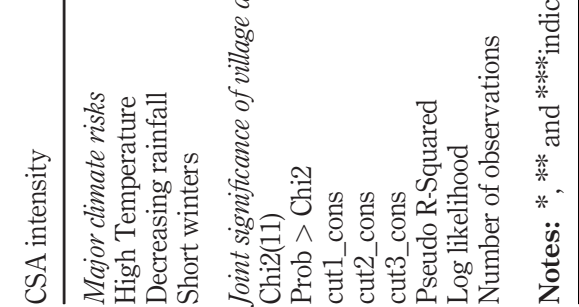

Table V. 


\section{Conclusions}

This study assessed the factors that determine the likelihood and intensity of adoption of CSAPs by the farmers of Bihar, India. Understanding barriers to and enabling conditions for the adoption of CSAPs helps in designing and formulating extension messages and agricultural policies that can accelerate the dissemination of CSAPs. Our results show that farmers adopt these CSAPs as complements and substitutes; however, there is greater scope for promoting complementarities among these CSAPs. Farmers' characteristics including gender, caste, education, social and economic capital, farm land characteristics, access to the market, extension services and training, and major climate risks experienced by the local farmers, are found to be some of the major factors affecting the decision to adopt the technology.

Access to markets and extension services is found to have a crucial role in increasing the uptake of CSAPs. Therefore, it is important to focus on policies and plans that improve market access and quality of public extension services. More training on CSAPs for farmers, more government extension staff working at the local level and the use of ICTs to share and promote knowledge of CSAPs are essential. In this case, mainstreaming CSAPs in village-level (local) climate-change adaptation plans and disseminating knowledge of new CSAPs to rural farmers through enhanced extension services is crucial. Another important issue of high concern is the increasing land fragmentation in Bihar and its implications on the adoption of CSAPs. Given that farmers operating larger farms are more likely to adopt CSAPs; it is important to facilitate agricultural land rental markets, mainly because acquiring land through land sale markets is beyond the capacity of the poor farmers. Therefore, agricultural policies should focus on the regulation of agricultural land rental markets in such a way that landlords do not need to compromise their property rights while renting land and, at the same time, efficient small farmers can access land through well-regulated land rental transactions.

\section{Acknowledgements}

The authors acknowledge the support of the CGIAR research program on Climate Change, Agriculture and Food Security (CCAFS) and CGIAR Research Program on Wheat Agri-Food Systems (CRP-WHEAT) for this study. They thank also to all field staff for their sincere efforts while collecting data in Bihar. Authors also sincerely thank Mr Amit Kumar Srivastava for his assistance in providing an excellent map of the study area. The views expressed here are those of the authors and do not necessarily reflect the views of the authors' institutions or CCAFS/CRP WHEAT. The usual disclaimer applies.

\section{References}

Aggarwal, P.K., Bhatta, G.D., Joshi, P.K., Prathapar, S.A., Jat, M.L. and Kadian, M. (2013), Climate Smart Villages in South Asia, Climate Smart Agriculture Learning Platform, South Asia, New Delhi.

Albert, S.M. and Duffy, J. (2012), "Differences in risk aversion between young and older adults", Neuroscience and Neuroeconomics, Vol. 2012 No. 1, pp. 1-12.

Aryal, J.P. and Holden, S.T. (2011), "Caste, investment and intensity of production", 18th Annual Conference, European Association of Environmental and Resource Economists (EAERE), 29 June - 2 July, Rome.

Aryal, J.P. and Holden, S.T. (2012), "Livestock and land share contracts in a Hindu society", Agricultural Economics, Vol. 43 No. 5, pp. 593-606.

Aryal, J.P. and Holden, S.T. (2013), "Land reforms, caste discrimination and land market performance in Nepal”, in Holden, S., Otsuka, K. and Deininger, K. (Eds), Land Tenure Reform in Asia and Africa, Palgrave Macmillan, Basingstoke, p. 25. 
IJCCSM 10,3

Aryal, J.P., Sapkota, T.B., Jat, M.L. and Bishnoi, D.K. (2015), "On-farm economic and environmental impact of zero-Tillage Wheat: a case of North-west India”, Experimental Agriculture, Vol. 51 No. 1, pp. 1-16.

Aryal, J.P., Farnworth, C.R., Khurana, R., Ray, S. and Sapkota, T.B. (2014), “Gender dimensions of climate change adaptation through climate smart agricultural practices in India", Innovation in Indian Agriculture: Ways Forward, Institute of Economic Growth (IEG), New Delhi, and International Food Policy Research Institute (IFPRI), New Delhi and Washington, DC.

Aryal, J.P., Sapkota, T.B., Stirling, C.M., Jat, M.L., Jat, H.S., Rai, M., Mittal, S. and Sutaliya, J.M. (2016), "Conservation agriculture-based wheat production better copes with extreme climate events than conventional tillage-based systems: a case of untimely excess rainfall in Haryana, India", Agriculture, Ecosystems \& Environment, Vol. 233, pp. 325-335.

Behera, B., Rahut, D.B., Aryal, J. and Ali, A. (2015), "Household collection and use of biomass energy sources in South Asia”, Energy, Vol. 85, pp. 468-480.

Belsley, D.A. (1991), "A Guide to using the collinearity diagnostics", Computer Science in Economics and Management, Vol. 4 No. 1, pp. 33-50.

Belsley, D.A., Kuh, E. and Welsch, R.E. (2005), Regression Diagnostics: Identifying Influential Data and Sources of Collinearity, John Wiley \& Sons, Hoboken, New Jersey.

Birthal, P.S., Kumar, S., Negi, D.S. and Roy, D. (2015), "The impacts of information on returns from farming: evidence from a nationally representative farm survey in India”, Agricultural Economics, Vol. 46 No. 4, pp. 549-561.

Bradshaw, B., Dolan, H. and Smit, B. (2004), "Farm-level adaptation to climatic variability and change: crop diversification in the Canadian Prairies", Climatic Change, Vol. 67 No. 1, pp. 119-141.

Chander, P. and Thangavelu, S.M. (2004), "Technology adoption, education and immigration policy", Journal of Development Economics, Vol. 75 No. 1, pp. 79-94.

D'Souza, G., Cyphers, D. and Phipps, T. (1993), "Factors affecting the adoption of sustainable agricultural practices", Agricultural and Resource Economics Review, Vol. 22 No. 2, pp. 159-165.

de Janvry, A., Fafchamps, M. and Sadoulet, E. (1991), "Peasant household behaviour with missing markets: some paradoxes explained", The Economic Journal, Vol. 101 No. 409, pp. 1400-1417.

Doss, C.R. (2003), Understanding Farm Level Technology Adoption: lessons Learned from CIMMYT's Micro Surveys in Eastern Africa, CIMMYT, Mexico, DF.

Erenstein, O. and Farooq, U. (2009), "A survey of factors associated with the adoption of zero tillage wheat in the irrigation plains of southAsia”, Experimental Agriculture, Vol. 45 No. 2, pp. 133-147.

Erenstein, O., Farooq, U., Malik, R.K. and Sharif, M. (2008), "On-farm impacts of zero tillage wheat in South Asia's rice-wheat systems", Field Crops Research, Vol. 105 No. 3, pp. 240-252.

FAO (2010), Climate-Smart Agriculture: Policies, Practices and Financing for Food Security, Adaptation and Mitigation, Food and Agriculture Organization of the United Nations, Rome.

FAO (2013), Climate-Smart Agriculture: Sourcebook, Food and Agriculture Organization of the United Nations, Rome.

Feder, G. and Umali, D.L. (1993), "The adoption of agricultural innovations: a review”, Technological Forecasting and Social Change, Vol. 43 Nos 3/4, pp. 215-239.

Government of Bihar (2012), State Action Plan on Climate Change: Building Resilience through Development, Government of Bihar, Bihar.

Greene, W.H. (2003), Econometric Analysis, Journal of the American Statistical Association, Education, P. (Ed.), Prentice Hall, Upper Saddle River, NJ.

Holden, S., Shiferaw, B. and Pender, J. (2001), "Market imperfections and land productivity in the Ethiopian highlands", Journal of Agricultural Economics, Vol. 52 No. 3, pp. 53-70.

Jöreskog, K.G. and Sörbom, D. (1993), LISREL 8: Structural Equation Modeling with the SIMPLIS Command Language, Scientific Software International, Chicago, IL. 
Kassam, A., Friedrich, T., Shaxson, F. and Pretty, J. (2009), "The spread of conservation agriculture: justification, sustainability and uptake", International Journal of Agricultural Sustainability, Vol. 7 No. 4, pp. 292-320.

Kassie, M., Heilemraim, T., Marenya, P., Jaleta, M. and Erenstein, O. (2015), "Production risks and food security under alternative technology choices in Malawi: application of a multinomial endogenous switching regression”, Journal of Agricultural Economics, Vol. 66 No. 3, pp. 640-659.

Kassie, M., Jaleta, M., Shiferaw, B., Mmbando, F. and Mekuria, M. (2013), "Adoption of interrelated sustainable agricultural practices in smallholder systems: evidence from rural Tanzania", Technological Forecasting and Social Change, Vol. 80 No. 3, pp. 525-540.

Kassie, M., Zikhali, P., Pender, J. and Köhlin, G. (2010), "The economics of sustainable land management practices in the Ethiopian highlands", Journal of Agricultural Economics, Vol. 61 No. 3, pp. 605-627.

Khatri-Chhetri, A., Aryal, J.P., Sapkota, T.B. and Khurana, R. (2016), "Economic benefits of climatesmart agricultural practices to smallholder farmers in the Indo-Gangetic plains of India", Current Science, Vol. 110 No. 7, pp. 1244-1249.

Lal, R. (1997), "Residue management, conservation tillage and soil restoration for mitigating greenhouse effect by $\mathrm{CO}_{2}$-enrichment”, Soil and Tillage Research, Vol. 43 Nos 1/2, pp. 81-107.

Lal, R. (2004), "Soil carbon sequestration impacts on global climate change and food security", Science, Vol. 304 No. 5677, pp. 1623-1627.

Liebman, M. and Dyck, E. (1993), "Crop rotation and intercropping strategies for weed management", Ecological Applications, Vol. 3 No. 1, pp. 92-122.

Lin, B.B. (2011), "Resilience in agriculture through crop diversification: adaptive management for environmental change", BioScience, Vol. 61 No. 3, pp. 183-193.

Mundlak, Y. (1978), "On the pooling of time series and cross section data", Econometrica, Vol. 46 No. 1, pp. 69-85.

Neufeldt, H., Jahn, M., Campbell, B.M., Beddington, J.R., DeClerck, F., De Pinto, A., Gulledge, J., Hellin, J., Herrero, M., Jarvis, A., LeZaks, D., Meinke, H., Rosenstock, T., Scholes, M., Scholes, R., Vermeulen, S., Wollenberg, E. and Zougmoré, R. (2013), "Beyond climate-smart agriculture: toward safe operating spaces for global food systems", Agriculture \& Food Security, Vol. 2 No. 1, p. 12.

Pender, J.L. and Kerr, J.M. (1998), "Determinants of farmers' indigenous soil and water conservation investments in semi-arid India", Agricultural Economics, Vol. 19 Nos 1/2, pp. 113-125.

Pingali, P.L. (2012), "Green revolution: impacts, limits, and the path ahead", Proceedings of the National Academy of Sciences, Vol. 109 No. 31, pp. 12302-12308.

Rao, N.H. (2007), "A framework for implementing information and communication technologies in agricultural development in India”, Technological Forecasting and Social Change, Vol. 74 No. 4, pp. 491-518.

Sapkota, T.B., Jat, M.L., Aryal, J.P., Jat, R.K. and Khatri-Chhetri, A. (2015), “Climate change adaptation, greenhouse gas mitigation and economic profitability of conservation agriculture: Some examples from cereal systems of Indo-Gangetic plains", Journal of Integrative Agriculture, Vol. 14 No. 8, pp. 1524-1533.

Sapkota, T.B., Majumdar, K., Jat, M.L., Kumar, A., Bishnoi, D.K., McDonald, A.J. and Pampolino, M. (2014), "Precision nutrient management in conservation agriculture based wheat production of northwest India: Profitability, nutrient use efficiency and environmental footprint", Field Crops Research, Vol. 155, pp. 233-244.

Sarkar, R.K., Reddy, J.N., Sharma, S. and Ismail, A.M. (2006), "Physiological basis of submergence tolerance in rice and implications for crop improvement”, Current Science, Vol. 91 No. 7, pp. 899-906.

Sehgal, V.K., Singh, M.R., Chaudhary, A., Jain, N. and Pathak, H. (2013), Vulnerability of Agriculture to Climate Change: District Level Assessment in the Indo-Gangetic Plains, Indian Agricultural Research Institute, New Delhi, ISBN: 978-81-88708-97-0. 


\section{IJCCSM 10,3}

Shiferaw, B., Aryal, J.P. and Mittal, S. (2012), "Cereal system diversification for sustainable productivity growth, climate risk management and adaptation in South Asia", 3rd International Agronomy Congress, New Delhi.

Singh, R.B. (2000), "Environmental consequences of agricultural development: a case study from the green revolution state of Haryana, India”, Agriculture, Ecosystems \& Environment, Vol. 82 Nos 1/3, pp. 97-103.

Teklewold, H., Kassie, M. and Shiferaw, B. (2013), "Adoption of multiple sustainable agricultural practices in rural Ethiopia”, Journal of Agricultural Economics, Vol. 64 No. 3, pp. 597-623.

Wollni, M., Lee, D.R. and Thies, J.E. (2010), “Conservation agriculture, organic marketing, and collective action in the Honduran hillsides", Agricultural Economics, Vol. 41 Nos 3/4, pp. 373-384.

Wu, J. and Babcock, B.A. (1998), "The choice of tillage, rotation, and soil testing practices: economic and environmental implications", American Journal of Agricultural Economics, Vol. 80 No. 3, pp. 494-511.

Yamano, T., Rajendran, S. and Malabayabas, M.L. (2015), "Farmers' self-perception toward agricultural technology adoption: evidence on adoption of submergence-tolerant rice in Eastern India", Journal of Social and Economic Development, Vol. 17 No. 2, pp. 260-274.

Yu, L., Hurley, T., Kliebenstein, J. and Orazem, P. (2012), "A test for complementarities among multiple technologies that avoids the curse of dimensionality”, Economics Letters, Vol. 116 No. 3, pp. 354-357.

\section{About the authors}

Jeetendra Prakash Aryal is a Climate Economist with the Socioeconomics Program in the International Maize and Wheat Improvement Center (CIMMYT). He joined CIMMYT from May 2012 and has been working in Climate Change, Agriculture and Food Security (CCAFS) in South Asia. His current works focus in identifying coping and adaptation strategies of farmers and the poor to manage future climate change. In addition, his work analyses the economic incentives and benefits to farmers from adoption of conservation agriculture for adaptation to and mitigating climate change in south Asia. Before joining CIMMYT, he worked as a researcher in the Norwegian University of Life Sciences, Norway. He had also served Tribhuvan University, Nepal as a lecturer of Economics. His main areas of interest are land productivity, land reforms, technology adoption, conservation agriculture, analysis of risk coping strategies of the farm households and climate change. Aryal obtained his MA in Mathematical Economics from Tribhuvan University, Nepal and MSc and PhD in Development and Resource Economics from the Norwegian University of Life Sciences, Norway.

M.L. Jat is a Senior Cropping Systems Agronomist (Principal Scientist) with CIMMYT's Sustainable Intensification Program and currently responsible for coordinating CIMMYT-CCAFS research in South Asia. Before joining CIMMYT, he served Indian Council of Agricultural Research (ICAR) for 12 years as Systems Agronomist and Conservation Agriculture Specialist. His significant research contributions in the fields of conservation agriculture, precision farming and climate change in major production systems of South Asia are well-documented in nearly 200 publications. A wellrecognized expert in the field of conservation agriculture (CA) and climate smart agriculture (CSA), M.L. is a recipient of large number of awards, honors and fellowships from national and international organizations and societies.

Tek B. Sapkota is Climate Change and Agricultural System Scientist working in Sustainable Intensification Program in the International Maize and wheat improvement Centre (CIMMYT). He obtained $\mathrm{PhD}$ in agro-biosciences (agriculture, environment and landscape) with specialization in nutrient dynamics in agro-ecosystem. His research interest includes analysis of cropping systems from food security climate change nexus. He is involved in studying management consequences on nutrient dynamics in agro-ecosystem and their effect on food security, poverty reduction, climate change adaptation and mitigation.

Arun Khatri-Chhetri is an agricultural economist at CCAFS-BISA, India. Prior to joining CCAFS, he has worked as a Research Consultant for Conservation International and International Food Policy Research Institute (IFPRI) Washington D.C. USA. He also worked as Research Associate in Davis College of Agriculture, Natural Resources and Design, West Virginia University, USA. He spent one year as a visiting researcher at the School of International Development and Cooperation, Hiroshima 
University, Japan. Dr Arun has over eight years of research and development experiences on socioeconomic and institutional aspects of natural resource management and conservation, agricultural production and food security, and vulnerability to climate change and adaptations. His key interests include agricultural and water resource management, adaptation options for climate change, sustainable use and protection of natural resources and ecosystems for human well-being, and market-based approach of natural resource management and conservation. Arun completed his $\mathrm{PhD}$ in Agriculture and Natural Resource Economics from West Virginia University, USA and has a Master degree in Agricultural Economics from Tribhuvan University, Nepal.

Menale Kassie is a Development Economist working at the International Centre of Insect Physiology and Ecology (ICIPE). Before joining ICIPE in 2015, he had been with the International Maize and Wheat Improvement Center (CIMMYT) for about five years. In CIMMYT, he coordinated the socioeconomic components of the program "Sustainable intensification of maize-legume cropping systems for food security in eastern and southern Africa (SIMLESA)" supported by the Australian Government through the Australian Center for International Agricultural Research (ACIAR). His research focuses on adoption and impact of crop and natural resource management technologies on rural household welfare, using advanced cross-section-panel econometrics and mathematical programing models.

Dr Dil Bahadur Rahut is currently working in International Maize and Wheat Improvement Center (CIMMYT) as Science Program Manager, Socioeconomics Program, CIMMYT. He holds a PhD in Development Economics from the University of Bonn, MA International Political Economy from Tsukuba University, Japan and MBA (Financial Management) from India. Before joining CIMMYT, Dil worked at South Asian University, Bank of Bhutan Limited, Indian Council for Research on International Economic Relations (ICRIER), WorldFish Centre, Centre for Development Research (ZEF) and Royal Monetary Authority of Bhutan. Applied economic research including households' decision-making under climate change and resource allocation are the research areas of Dil Bahadur Rahut. Dil Bahadur Rahut is the corresponding author and can be contacted at: dilbhutan@gmail. com

Sofina Maharjan is an Economist working in the International Maize and Wheat Improvement Centre (CIMMYT). She is a consultant for the project entitled "Sustainable and Resilient Farming System Intensification (SRFSI)". She has worked in several projects related to climate change such as Climate Change, Agriculture and Food Security (CCAFS) and Adoption and Impact of Laser Land Leveling in India, She received MA in economics from the South Asian University, India.

For instructions on how to order reprints of this article, please visit our website: www.emeraldgrouppublishing.com/licensing/reprints.htm Or contact us for further details: permissions@emeraldinsight.com 